\title{
The Impact of an ICU Liaison nurse Program on Physiological Parameter and Level of Consciousness in Discharging Patients in the Intensive Care Unit: A Randomized Clinical Trial
}

\section{Ensieh Elyasi', Mahnaz Khatiban², Younes Mohammadi ${ }^{3}$, Morteza Shamsizadeh ${ }^{* 4}$}

1. Student Research Committee, School of Nursing and Midwifery, Hamadan University of Medical Sciences, Hamadan, Iran

2. Professor, Department of Medical Surgical Nursing, School of Nursing and Midwifery, Hamadan University of Medical Sciences, Hamadan, Iran

3. Associate Professor, Department of Epidemiology, School of Health, Hamadan University of Medical Sciences, Hamadan, Iran

4. Instructor, Department of Medical Surgical Nursing, School of Nursing and Midwifery, Hamadan University of Medical Sciences, Hamadan, Iran

\begin{tabular}{l} 
Article Info \\
\hline Received: $2019 / 02 / 20 ;$ \\
Accepted: $2019 / 05 / 06 ;$ \\
Published Online: $2020 / 01 / 17$
\end{tabular}

10.30699/ajnmc.28.3.227

Original Article

Use your device to scan and read the article online

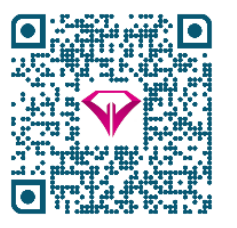

\section{ABSTRACT}

Introduction: Patients transferred from ICU to general ward need a higher level of nursing attention and care than other patients admitted to the ward. The aim of this study was to investigate the effect of the role of the liaison nurse on physiological indicators and the level of consciousness of patients transferred from the intensive care unit.

Methods: The present article is the result of a two-group clinical trial that was performed on 90 patients admitted to the special and general wards of Besat Hospital in Hamadan, Iran. Available sampling and patients were randomly assigned to the two groups. The control group received routine care and in the intervention group was visited twice a day by the liaison nurse for up to three days. The instrument used was a checklist of physiological indices and the GCS scale. Mean, standard deviation, variance and frequency percentage were used to describe the data by SPSS 16.

Results: There was no significant difference between the demographic and clinical characteristics of the two groups at the beginning of the study. After the intervention of the intensive care unit nurse, the two groups were not significantly different in terms of physiological parameters and level of consciousness $(P>0.05)$.

Conclusion: In nursing services, the interface is not effective on physiological indicators and level of consciousness in patients transferred from the intensive care unit to the general ward. Further studies in this area are recommended.

Keywords: Liaison nurse, Physiological indices, Intensive care unit, Level of consciousness

\section{How to Cite This Article:}

Elyasi E, Khatiban M, Mohammadi Y, Shamsizadeh M. The Impact of an ICU Liaison nurse Program on Physiological Parameter and Level of Consciousness in Discharging Patients in the Intensive Care Unit: A Randomized Clinical Trial. Avicenna J Nurs Midwifery care. 2020; 28 (3) :227-238 
تاثير نقش :يرستار رابط بر شاخصهاى فيزيولوزيك و سطح هوشيارى بيماران انتقالى از بخش مراقبتهاى ويزه: يك مطالعه كار آزمايى بالينى

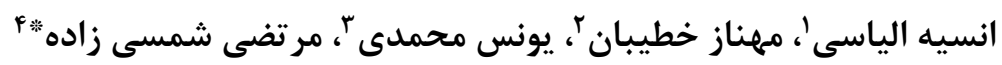

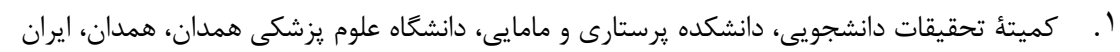

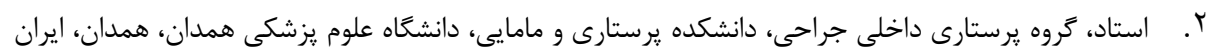

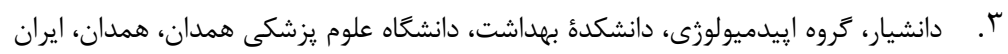

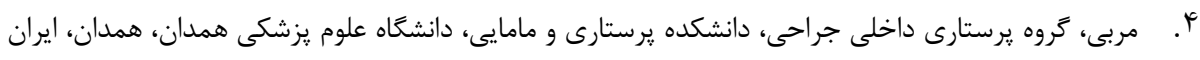

\begin{tabular}{|c|c|}
\hline جكيده & 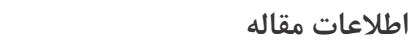 \\
\hline & 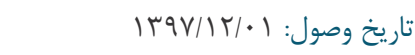 \\
\hline 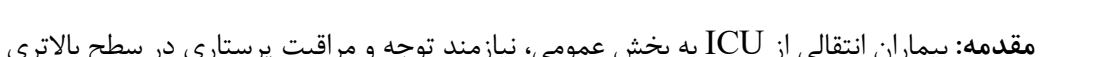 & 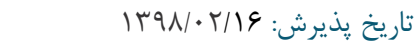 \\
\hline 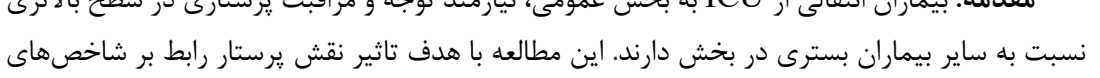 & 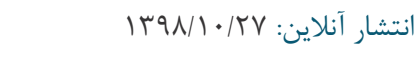 \\
\hline فيزيولوزيك و سطح هوشيارى بيماران انتقالى از بخش مراقبتهاى ويزه انجام شد & نو يسندهُ مسئول: \\
\hline روش كار: مقاله حاضر، حاصل يك كارآزمايى بالينى دو كروهى است كه در بخشهاى ويزه و عمومى & 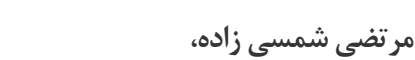 \\
\hline بيمارستان بعثت همدان بر روى •و بيمار بسترى انجام شد. نمونهَيرى در دسترس و بيماران به دو گروه & خلى جراحى، \\
\hline به صورت تخصيص تصادفى، تخصيص يافتند. گروه كنترل مراقبتهاى معمول را دريافت كردند و در گروه & دانشكده يرستارى و مامايى، دانشعاه \\
\hline 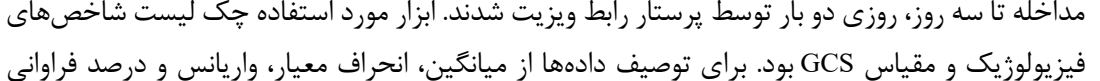 & 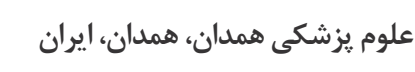 \\
\hline توسط نرم افزار SPSS نسخه 1 استفاده شد. & يسن \\
\hline يافتهها: اختلاف معنى دارى بين مشخصات دموكرافيك و بالينى دو گروه در ابتداى مطالعه مشاهده & mortezashamsizadeh@gmail.com \\
\hline 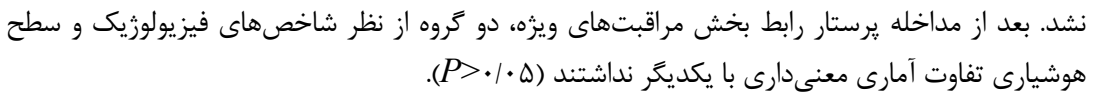 & براى دانلود اين مقاله، كد زير را \\
\hline نتيجه گيرى: در خدمات يرستار رابط بر شاخصهاى فيزيولوزيك و سطح هوشيارى در بيماران انتقالى & 田 \\
\hline از بخش مراقبتهاى ويزه به بخش عمومى موثر نيست. مطالعات بيشتر در اين زمينه توصيه مى كردد. & 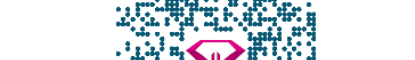 \\
\hline كليدوازهها: يرستار رابط، يارامترهاى فيزيولوزيكى، بخش مراقبتهاى ويزه، سطح هوشيارى & 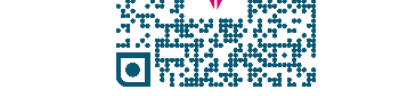 \\
\hline
\end{tabular}

به افزايش بيمارى هاى مزمن و هم جنين روند درمان آنها كه

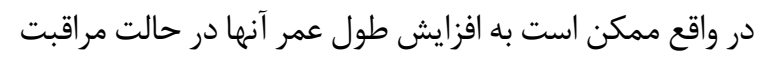

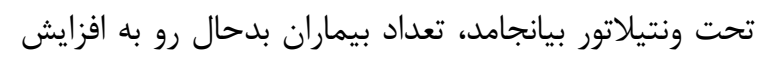

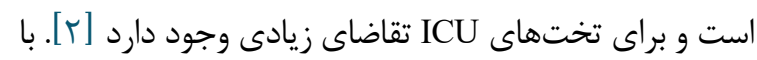

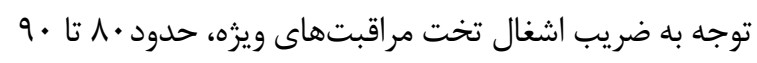

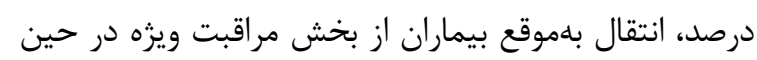

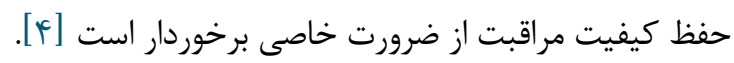

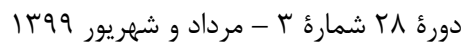

واحد مراقبت ويزه (ICU)' يك مركز ويزه در بيمارستان است مخصوص مراقبت از افراد دجار بيمارىها يا جراحات

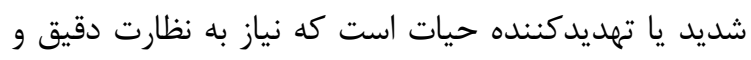

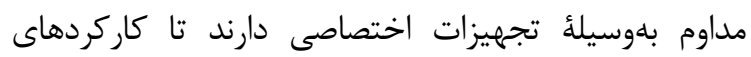

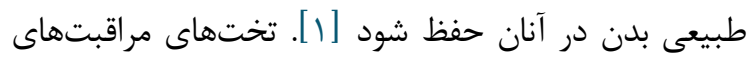
ويزه (ICU) از منابع گران و كمياب در بسيارى از بيمارستانها

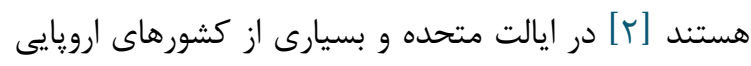

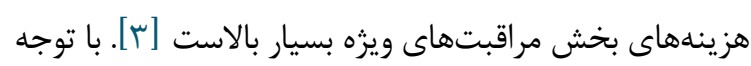

Intensive care unit -' 
يرستاران بخشهاى عمومى دانش و مهارت لازم براى مراقبت

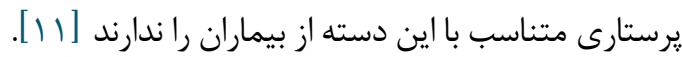

يرستارى رابط از مراقبتهاى بالينى مدرن و كاربردى است كه در دهdهاى اخير به علت افزايش تكنيكهاى مراقبتى

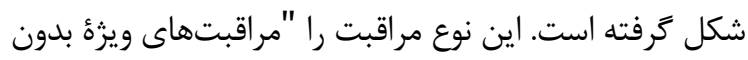

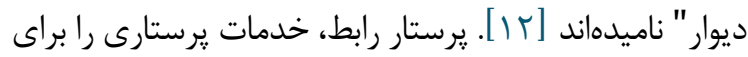
بيماران كسترش داده و موجب تسهيل مراقبت از بيماران

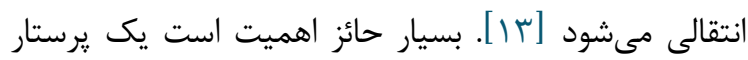
رابط بتواند خلاهاى موجود را تر نمايد. يرستار رابط يرستارى است كه در بخش مراقبت ويزه كار مى كند و به روند درمان بيمار آكاه است [بار]. بسيارى از تحقيقات، حضور

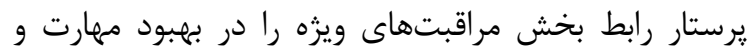

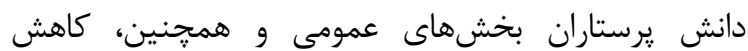

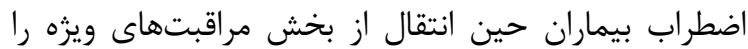

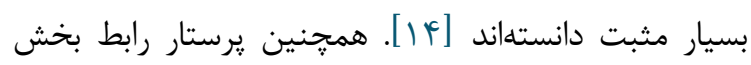
مراقبتهاى ويزه موجب بهبود يِيامدهاى ترخيص، كاهش اضطراب خانواده و كاهش زمان بسترى شدن در بيمارستان

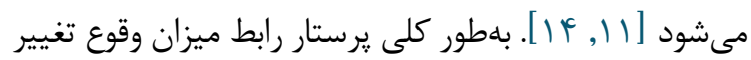
وضعيت سلامت بيمار به شرايط حاد و نياز به بسترى مجدد بـان

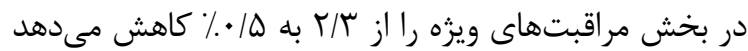

[1 10$]$

مسؤليتهاى يرستار رابط شامل تسهيل در مراحل انتقال با ايجاد آمادگى و آحاهى در بيمار و خانوادهٔ بيمار از علت

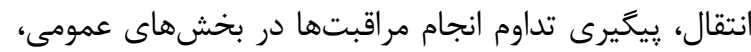
بررسى اقدامات انجامشده در بخشهاى عمومى، مديريت

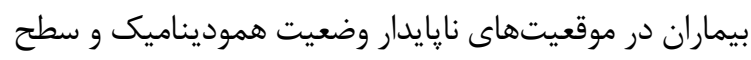
سلامتى، حمايت بيمار در برنامههاى خودمراقبتى، آموزش به

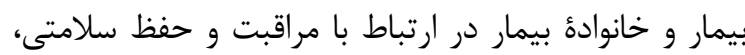

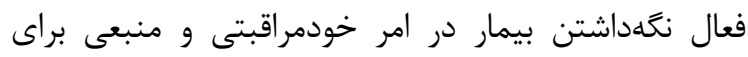

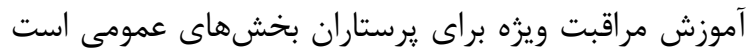

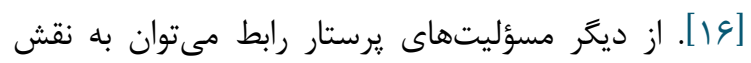

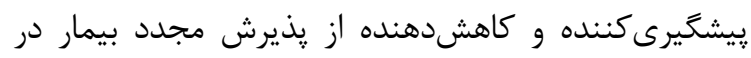
بخش مراقبتهاى ويزه، تسهيل در مداخلات بهموقع يرستاران بخشهاى عمومى، تقويت ارتباط و هماهنكى بين يرستار بخشهاى مراقبت ويزه و يرستاران بخشهاى تحفيت عمومى اشاره

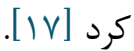

بين بخش مراقبتهاى ويزه و بخش عمومى تفاوتهاى مشخصى از نظر محيط و تكنولوزى ييشرفته ICU و تعداد

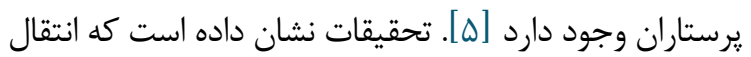
أ نياز به برنامهريزى جدى دارد و قبل و بعد از انتقال

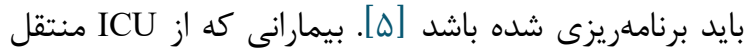

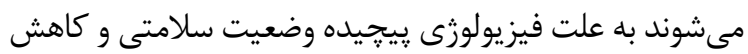

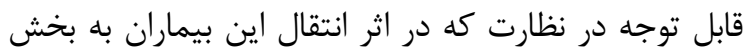

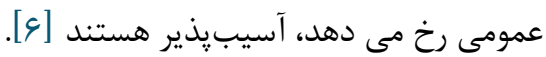
ترخيص از بخش مراقبتهاى ويزه (ICU) با تعدادى از

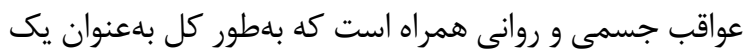
سندرم يس از مراقبتهاى ويزه (PICS) شناخته مىشود كه

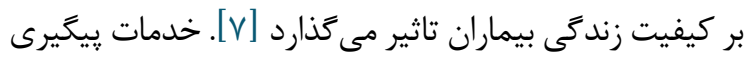

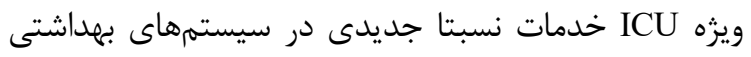

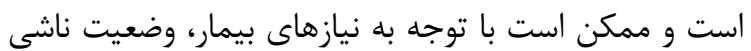

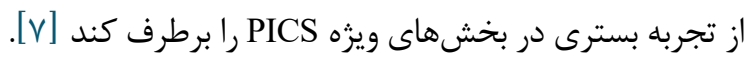

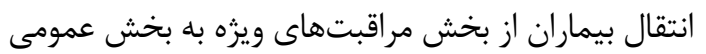

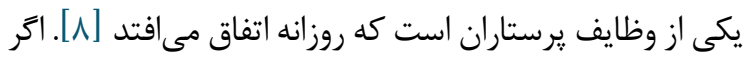
اين امر بلهور صحيح و موثر انجام شود، موجب كاهش

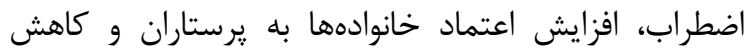

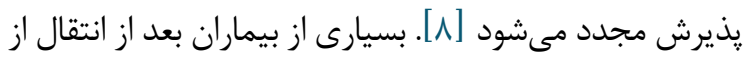

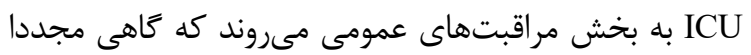
در بسترى مىشوند و يا حتى مىميرند كه دلائل

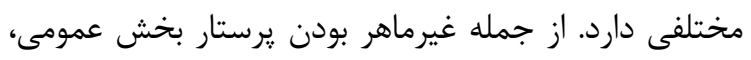

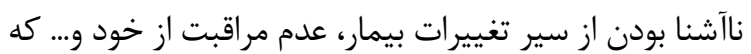

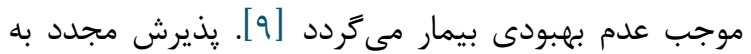
بخش مراقبتهاى ويزه عوارضى را براى بيمار و سيستم

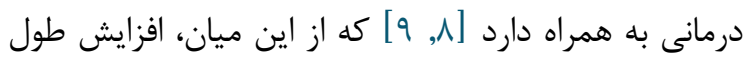

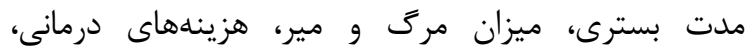
عفونتهاى بيمارستانى و ايجاد استرس مضاعف براى بيمار و و خانوادة وى مشاهده مىشود [ [1]. انتقال بيمار از بخش مراقبتهاى ويزهن فرايند ييبيجيدهاى

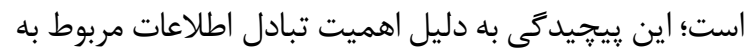

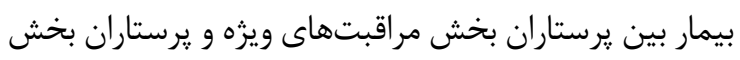

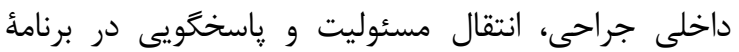

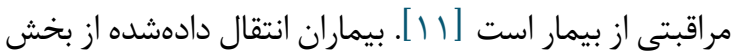

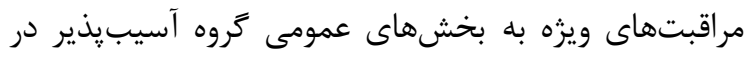

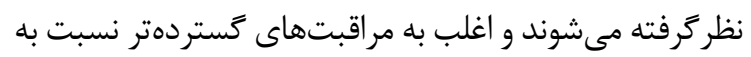
ساير بيماران بسترىشده در آن بخشها نيازمندند كه اغلب 
هوشيارى اينكونه بيماران داشته باشد. تجربؤ يزوهشكر در

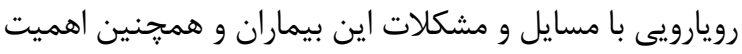
موضوع و عدم وجود تحقيقات كافى در اين زمينه، و نبود

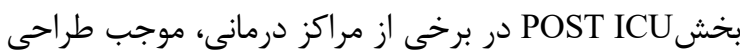

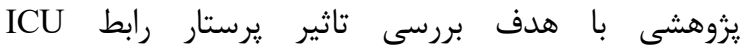

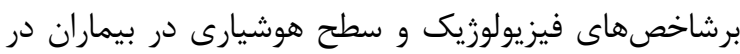
حال ترخيص از بخش مراقبتهاى ويزه شد.

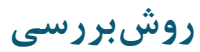

مقالة حاضر، حاصل يك كار آزمايى بالينى دو تروهى در بخش مراقبتهاى ويزه و بخش عمومى بيمارستان بعثت شهر همدان در دران

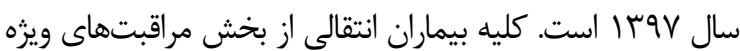

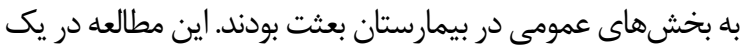

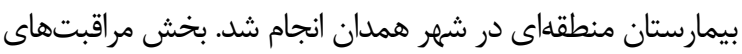

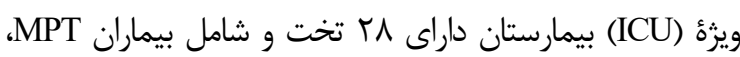
جراحىهاى عمومى و عروقى، بيمارىهاى نرولوزيك و ...) است.

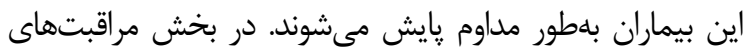

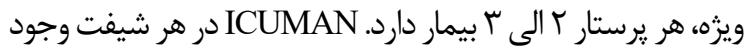
دارد كه بيماران را ويزيت مى كند. بخش عمومى شامل • ب تخت است كه در شيفت صبح توسط ץ يرستار و در شيفتهاى عصر و

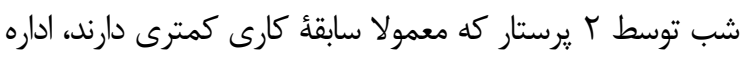

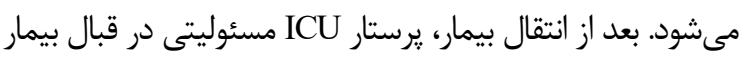
و وضعيت بالينى وى در بخش ندارد. بيمار در بخش عمومى در

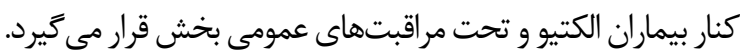
به مراقب (مراقبين)، آموزشهاى لازم براى مراقبت از بيمار داده نمىشود و امكانات لازم جهت مانيتورينگ مداوم بيماران وجود

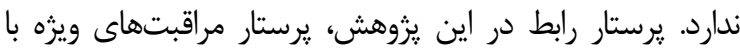

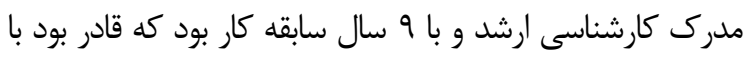
استفاده از مطالعات و تجارب خود، اهداف خود را تحقق بخشد. معيارهاى ورود براى بيماران: بسترى در بخش مراقبتهاى ويزه كه

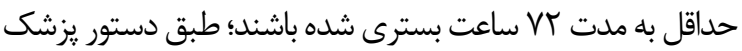

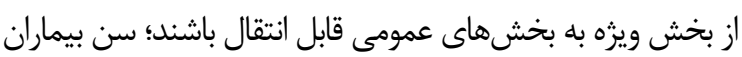

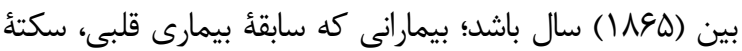
مغزى، بيمارىهاى خودايمن، سرطان، ايست قلبى تنفسى و

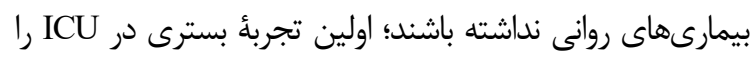

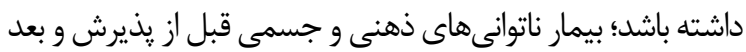
از ترخيص از ICU إ انداشته باشد.
يرستاران نقش مهمى در افزايش كيفيت مراقبت،

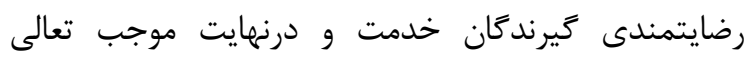

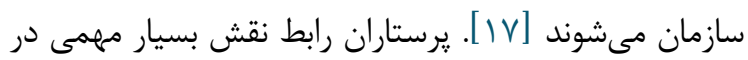

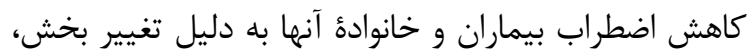
نبودن امكانات و دستخاههاى مجهز بخش مراقبتهاى ويزه در بخش داخلى -جراحى، عدم حضور دايمى يرستاران بر بالين

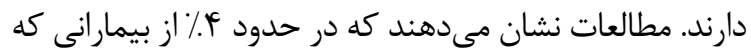

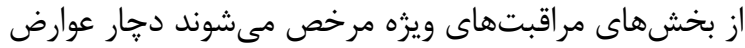
جانبى مانند اضطراب و استرس (تغييرات علايم حياتى دارند)

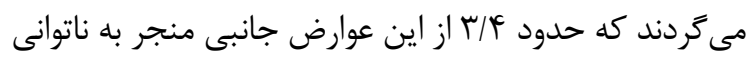

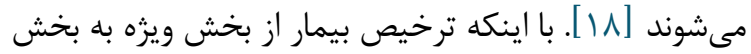
عمومى قدم مثبت محسوب مىشود ولى بيمار و خانوادهاش

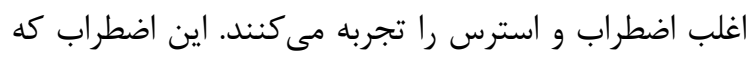

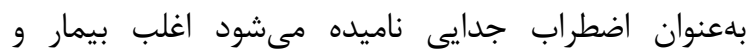

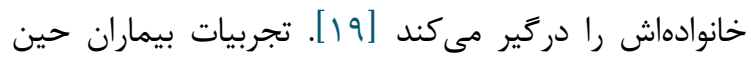

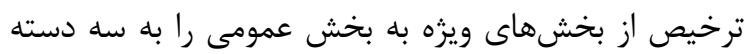

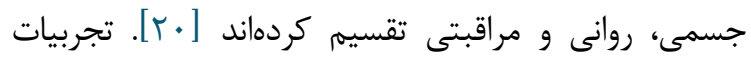
بيماران از يك احساس مثبت شامل مستقل بودن تا احساس منفى شامل اضطراب و استرس مىتواند متفاوت باشد [1/r]. بسيارى از تحقيقات حضور يرستار رابط بخش مراقبت إتبتهاى

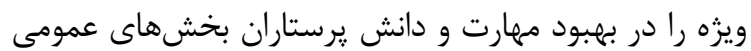

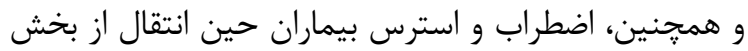

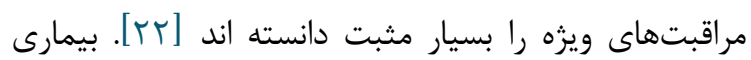
جدى و ورود به بخش مراقبتهاى ويزه (ICU) يك تجربه التبيه تهاجمى است كه مىتواند منجر به تحول قابل ملاحظهاى در

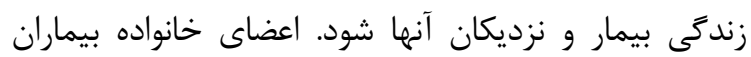
بدحال اغلب با افزايش مشكالت روحى و جسمى روبرو هستند

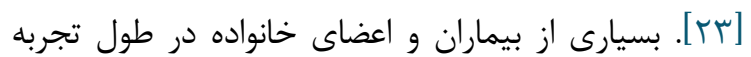

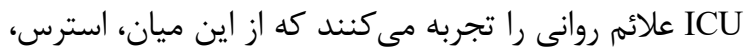

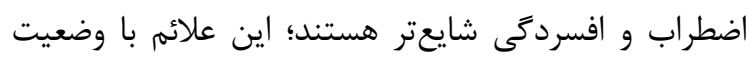

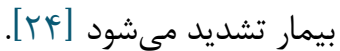

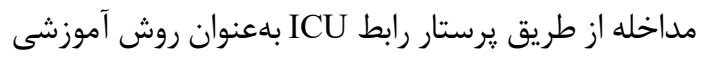

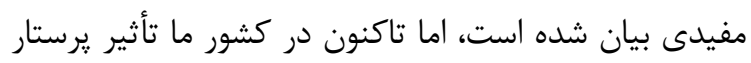

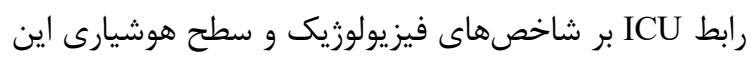
بيماران به خوبى مورد توجه يزوهشكران قرار نكرفته است. از

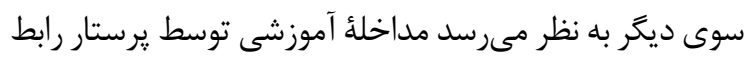
ا كه خود تجربه كافى در مورد برخورد با بيماران ICU ICU

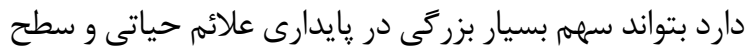


(اكسيرن، ساكشن، بخور، تشك مواج و...) و وضعيت اطاق را از نظر

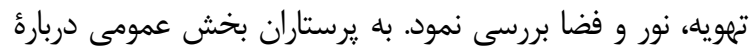

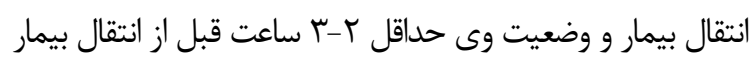
اطلاعرسانى شد. ب- مراقبت و حمايت جسمى و عاطفى از بيمار و آموزش به او: قبل از انتقال، وضعيت جسمى و روانى بيمار با دقت مورد بر برسى إنى قرار كرفت. به بيمار در مورد علت انتقال وى به به بخش، بندئ امكانات

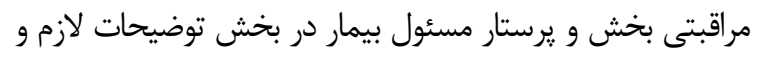

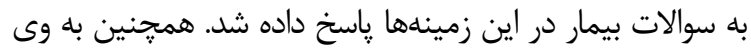

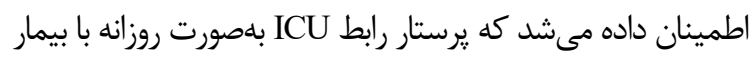

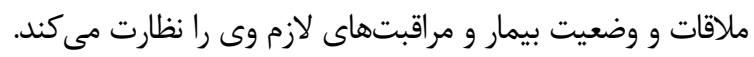

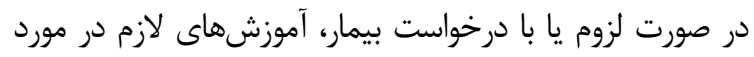

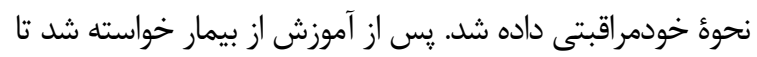

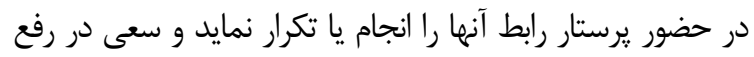

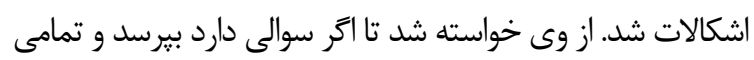

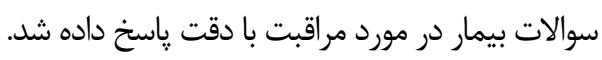

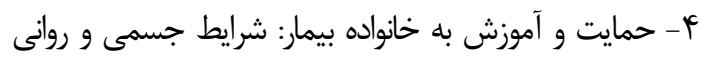

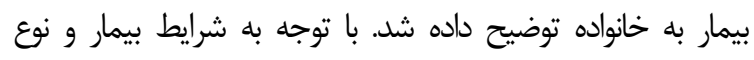

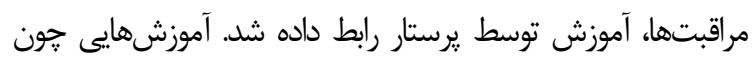

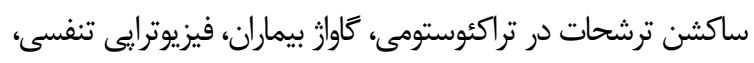

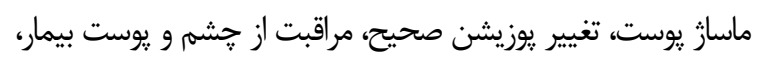

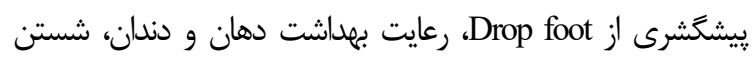

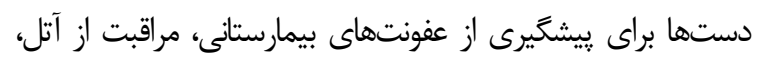

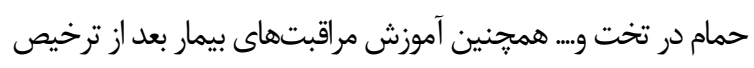

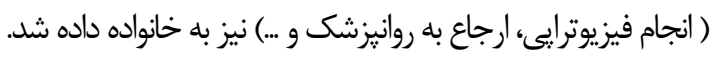

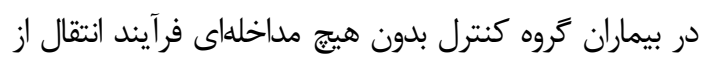
بخش مراقبتهاى ويزه به بخش عمومى انجام و در فواصل زمان بران

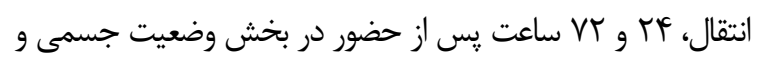

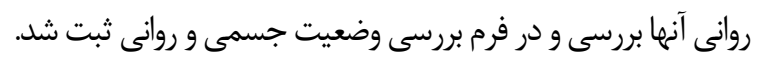

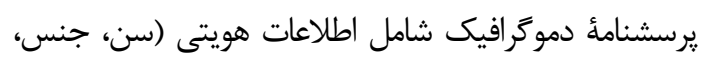
تاهل، محل سكونت، شغل، وزن، قد، شاخص توده بد بدنى،

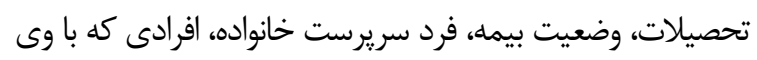

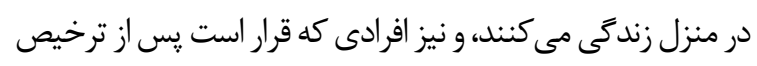

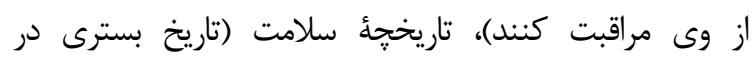

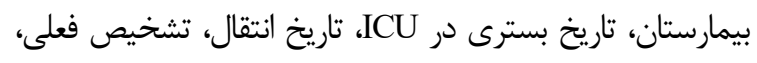

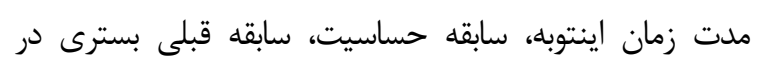

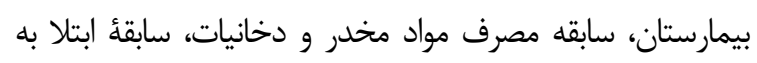

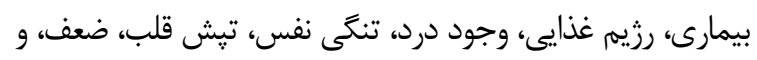

قرار كرفتن بيمار كروه كنترل و آزمون در يك اطاق و انصراف

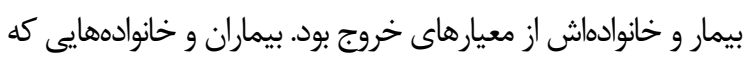
شرايط ورود به مطالعه را داشتند شناسايى شدند. سيس بران براى انتخاب

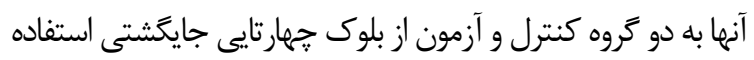

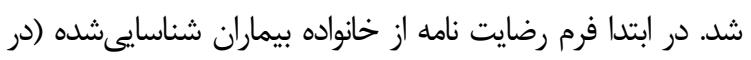
صورت تمايل به شركت در اين يزوهش) كرفته شد. بعد از دستور

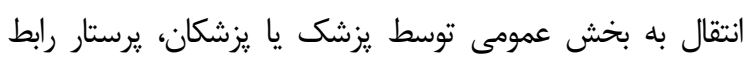

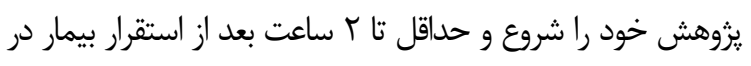

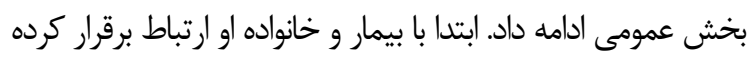

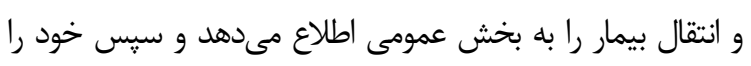
بلعنوان يرستار رابط معرفى مى كند. در هر دو كروه آزمون و كنترل

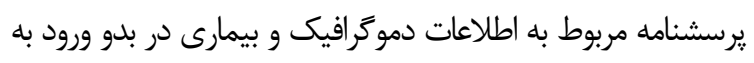

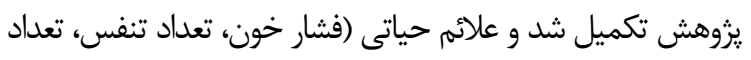

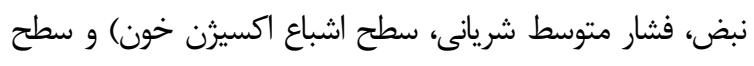

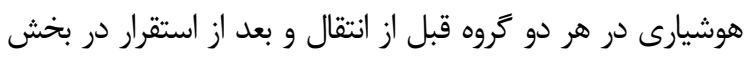
عمومى توسط يرستار رابط كنترل و ثبت شد. در كروه كرو كنترل،

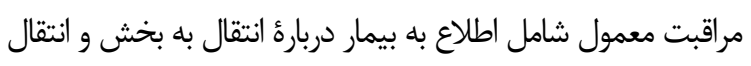

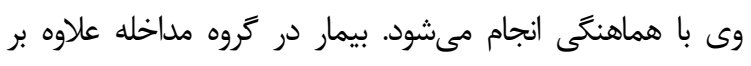

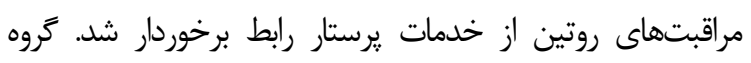

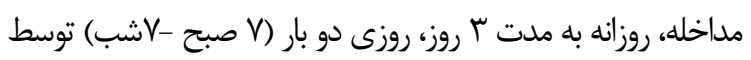

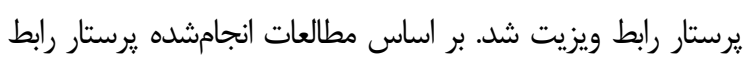
ICU

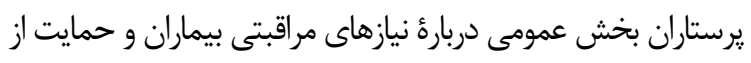

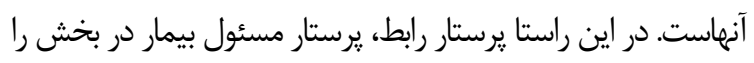

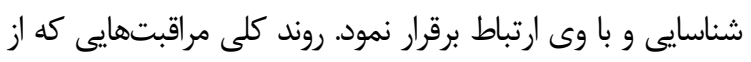

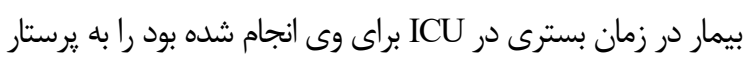

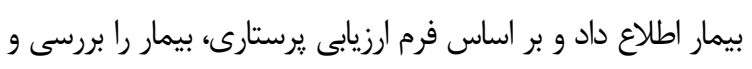

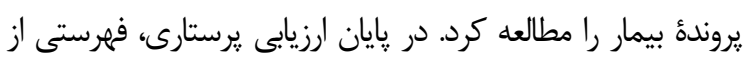

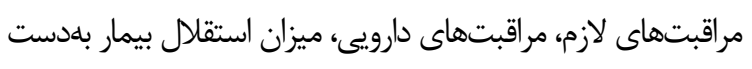

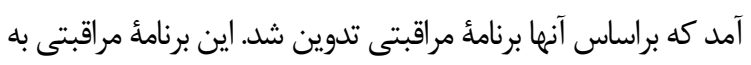

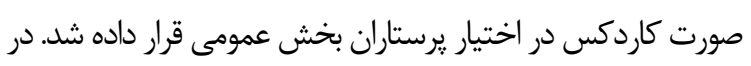

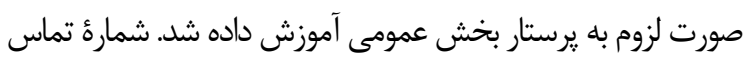

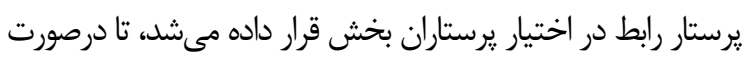
نياز باوى در تماس باشند.

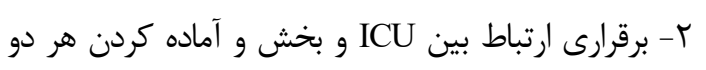
بخش براى فرآيند انتقال: در اين راستا يرستار رابط قبل از انتقال

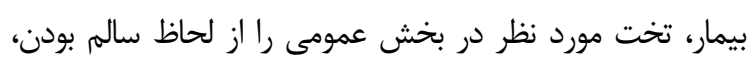
يوزيشندهى و داشتن نرده كنار تخت و نيز امكانات مورد نياز بيمار 
با معيار كلاسكو (GCS) به ياسخ كلامى تكيه نمى كند. در ICU)

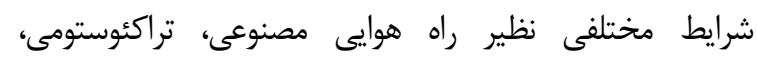

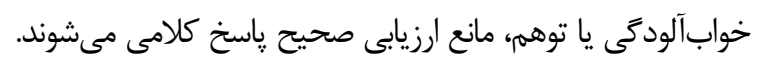

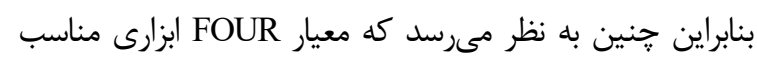

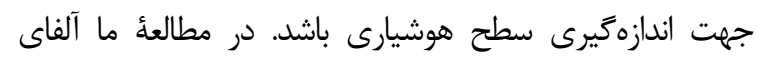
كرونباخ اين مقياس 99/9٪ بيان شده است. روش تجزيه و تحليل دادهها: جهت تجزيه و تحليل دادهها از

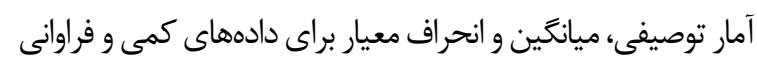

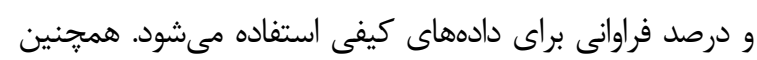

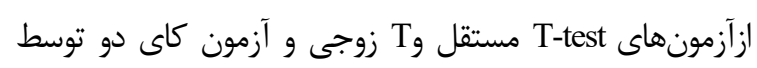
نرمافزار SPSS نسخه 19 (SPS Inc., Chicago, Ill., USA)

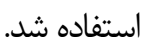

بافته ها

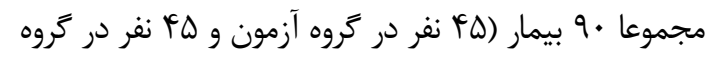

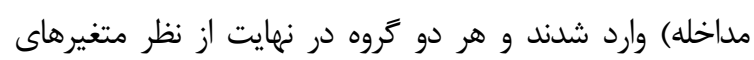

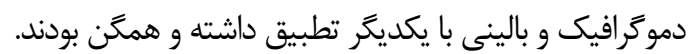

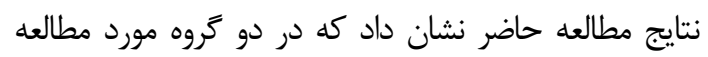

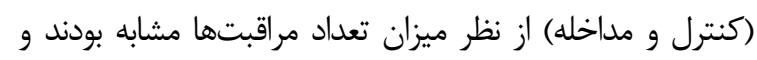

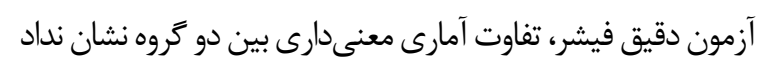
(ه • (P>). لذا هر دو گروه از اين نظر همَن بودند.
نيز وجود اختلالات در خواب، اشتها، دفع مدفوع و ادرار، همجنين

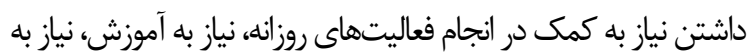
داشتن اطلاعات، وضعيت تحرك) براى جمع آورى دادهها استفاده شد. همجنين فرم تعيين نوع و مشخصات مراقبتهاى لازم براى بيمار (مراقبت از دهان، بهداشت فردى، سوند فولى، سوند معده، تراكئوستومى،كلستومى، يانسمان، سوجور، درن، تراكشن، آتل يا

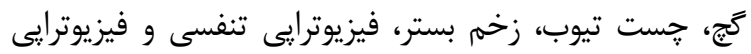
اندامها) نيز استفاده شد.

فرم ثبت وضعيت هوشيارى بيمار شامل دو قسمت زير بود. الف) معيار كلاسكو Glasgow Coma (GCS براى كنترل سطح هوشيارى بيمار كه معيارى استاندارد براى تعيين هوشيارى

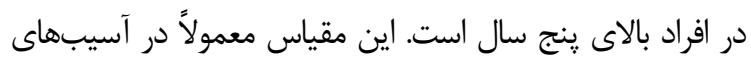

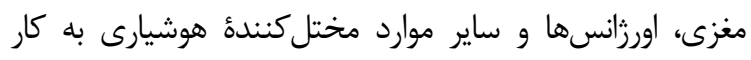

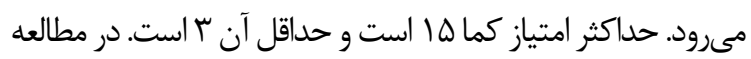
آلفاى كرونباخ سی.٪ بيان شد.

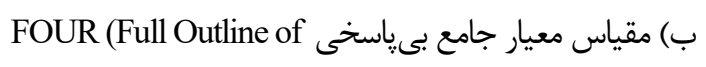

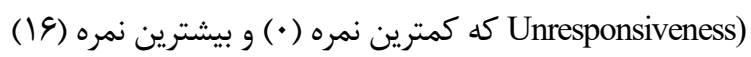
است. اين معيار در سال ه •.r توسط محققان كلينك مايو و براى ارزيابى تغييرات سطح هوشيارى يِيشنهاد (Mayo Clinic)

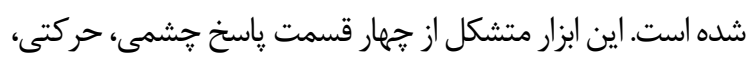
رفلكس ساقه مغز و الكوى تنفسى است. معيارFOUR در مر مقايسه

جدول ا. مقايسه توزيع فراوانى نوع مراقبتهاى روزانه در دو كروه كنترل ومداخله

\begin{tabular}{|c|c|c|c|c|c|}
\hline \multirow{2}{*}{ نتايج آزمون كاى دو } & \multicolumn{2}{|c|}{ كنترل } & \multicolumn{2}{|c|}{ 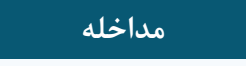 } & \multirow{2}{*}{ نوع مراقبتها } \\
\hline & درصد & تعداد & درصد & 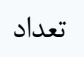 & \\
\hline $\mathrm{X}^{\mathrm{r}}=\cdot \mathrm{df}=1 \mathrm{P}=.199$ & $1 \cdots 1$ & $\uparrow \Delta$ & $1 \cdots$ & Fa & مراقبت از دهان \\
\hline$X^{r}=\cdot d f=1 P=\cdot / 99$ & $1 \cdots$ & $\notin \Delta$ & $1 \cdots 1$ & Fa & 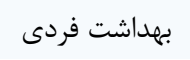 \\
\hline $\mathrm{X}^{\mathrm{r}}=\cdot \mathrm{df}=.1 \mathrm{P}=. / 99$ & $1 \cdots 1$ & $F \Delta$ & $1 \cdots 1$ & Fa & 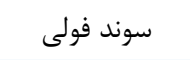 \\
\hline $\mathrm{X}^{\mathrm{r}}=\cdot / \cdot \mathrm{df}=1 . \quad \mathrm{P}=\cdot / 99$ & $11 / 1$ & $\Delta$ & $11 / 1$ & $\Delta$ & سوند معده \\
\hline $\mathrm{X}^{r}=\cdot / r|r \cdot \mathrm{df}=1, \mathrm{P}=\cdot| 9 \Delta r$ & G/V & r & $\boldsymbol{f} / \boldsymbol{f}$ & r & ت اكئوستومى \\
\hline$X^{r}=r / \cdot r \Delta \cdot d f=1, P=\cdot / / \Delta r$ & $\cdot /$ & - & $f / f$ & r & 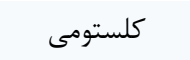 \\
\hline$X^{r}=\cdot / \cdots \cdot d f=1 ، P=\cdot / 99$ & $\wedge \& / \vee$ & rq & $\wedge \& / \vee$ & rq & 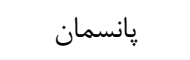 \\
\hline $\mathrm{X}^{r}=\cdot / 1 \cdot \uparrow, \mathrm{df}=1, \mathrm{P}=\cdot / \mathrm{r} \wedge$ & $\Lambda 9 / \mathrm{V}$ & rq & $\wedge N / 9$ & $r$. & سوجور \\
\hline $\mathrm{X}^{\mathrm{r}}=1 \cdot 1948, \mathrm{df}=1, \mathrm{P}=\cdot 1 \cdot \cdot 1$ & $r M / l$ & If & $f / f$ & r & 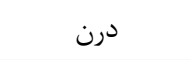 \\
\hline$X r=\cdot / 1 \Delta \Delta \cdot d f=1, P=\cdot / \varepsilon q \uparrow$ & $\varepsilon / V$ & r & N/9 & f & 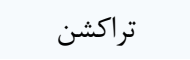 \\
\hline$X^{r}=\cdot / r \wedge \Delta \cdot d f=1, P=\cdot / \Delta r \Delta$ & $11 / 1$ & $\Delta$ & $\mid Q / 9$ & v & آتل يا كَج \\
\hline$X^{r}=1 / \cdot r q$, df $=1$ ، $P=\cdot / r 1$. & $r \& / V$ & ir & $I V / \Lambda$ & $\wedge$ & جست تيوب \\
\hline$X^{r}=r / \cdot r \Delta \cdot d f=1, P=\cdot / / \Delta r$ & $f / f$ & r & $\cdot$ & - & 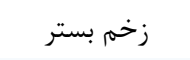 \\
\hline $\mathrm{X}^{\mathrm{r}}=\cdot / \cdot, \mathrm{df}=1 . \mathrm{P}=\cdot / 99$ & $9 \Delta / 9$ & er & $90 / 9$ & kr & فيزيوترابى تنفسى \\
\hline
\end{tabular}


انسيه الياسى و همكاران سبr
$\mathrm{X}^{\mathrm{r}}=1 / 99 \wedge, \mathrm{df}=1, \mathrm{P}=\cdot / 19 \mathrm{~V}$
$r \& / V$
it
$10 / 9$

جدول r. مقايسه ميانگين و انحر اف معيار شاخصهاى فيزيولوزيك بيماران قبل از انتقال از ICU به بخشهاى عمومى در دو گروه مداخله

\begin{tabular}{|c|c|c|c|c|c|}
\hline \multirow{2}{*}{ آزمون T } & \multicolumn{2}{|c|}{ مداخله } & \multicolumn{2}{|c|}{ كنترل } & \multirow[t]{2}{*}{ تروه ها } \\
\hline & انحراف معيار & ميانغين & انحراف معيار & ميانگين & \\
\hline 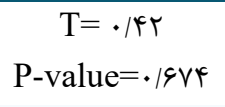 & $1 \cdot / F T A$ & $\| V / F A \Lambda$ & $|N / F| T$ & WN/ATT & 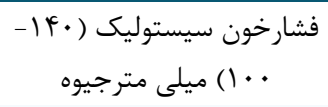 \\
\hline $\begin{array}{c}\mathrm{T}=\cdot / \mathrm{T}_{\mathrm{I}} \\
\mathrm{P} \text {-value }=\cdot / \mathrm{V} \Delta \mathrm{V}\end{array}$ & $1 / r q$ & $v \cdot 19$. & $11 / 11$ & 99/94 & فشارخون دياستوليك (9-9) ميلى متر جيوه \\
\hline $\begin{array}{c}\mathrm{T}=-\cdot / r q \\
\text { P-value }=\cdot / \text { vq }\end{array}$ & $\Lambda / \& \Lambda$ & $\Lambda \bowtie / \& q$ & $\mid r / \cdot T$ & $\Lambda \& / T V$ & 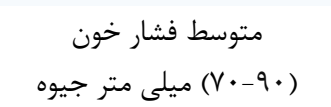 \\
\hline $\begin{array}{c}\mathrm{T}=\cdot / \Delta \& \mathrm{r} \\
\text { P-value }=\cdot / \Delta \mathrm{V} \Delta\end{array}$ & $11 / 91$ & $M N / T F$ & $10 / T q$ & AG/TT & 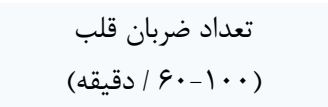 \\
\hline $\begin{array}{c}\mathrm{T}=-\Delta / \varphi . \\
\text { P-value }=\cdot / \cdot \cdot 1\end{array}$ & $\cdot / V^{c}$ & $10 / V G$ &.$/ 9 V$ & $19 / \mathrm{V} \Lambda$ & 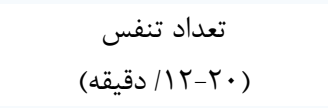 \\
\hline $\begin{array}{c}\mathrm{T}=-r / r \varphi \\
\mathrm{P} \text {-value }=\cdot / \cdot r .\end{array}$ & $\cdot / 1 F$ & $r V / \cdot r$ & r & $r V / I Q$ & 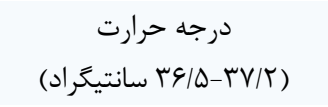 \\
\hline $\begin{array}{c}\mathrm{T}=\boldsymbol{F} / \mathrm{V} F \\
\mathrm{P} \text {-value }=\cdot / \mathcal{F} \boldsymbol{}\end{array}$ & $\cdot / \cdot 1$ & 90 & $\cdot / \cdot r$ & q & ( \\
\hline
\end{tabular}

تفاوت معنى دارى وجود ندارد. لذا هر دو گروه از اين نظر همگن

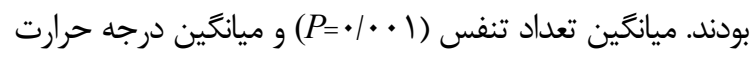

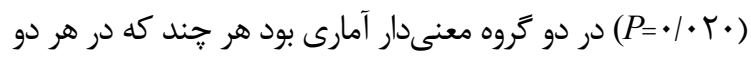

زروه در محدودههاى طبيعى بودند.
نتايج آزمون T مستقل در جدول فوق نشان مى دهدكه ميانگين فشار خون سيستول (PVF) (P=•/VDV)

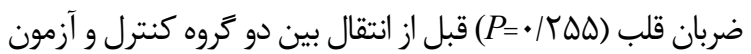

جدول ب. مقايسه ميانكين و انحراف معيار شاخصهاى فيزيولوزيك بيماران در پايان مطالعه در دو گروه مداخله

\begin{tabular}{|c|c|c|c|c|c|}
\hline \multirow{2}{*}{ آزمون } & \multicolumn{2}{|c|}{ مداخله } & \multicolumn{2}{|c|}{ كنترل } & \multirow{2}{*}{ متغير } \\
\hline & انحراف معيار & ميانگين & انحراف معيار & ميانگين & \\
\hline $\begin{array}{c}\mathrm{T}=\cdot / 9 \wedge 9 \\
\mathrm{df}=\wedge \Lambda \\
\text { P-value }=\cdot / \uparrow q r\end{array}$ & $10 / 999$ & $119 / \Gamma \Delta \varepsilon$ & IN/Fat & ITI/AFE & 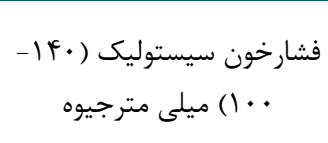 \\
\hline $\begin{array}{c}\mathrm{T}=\cdot / \cdot \Delta \mathrm{F} \\
\text { P-value }=\cdot / 9 \Delta \mathrm{V}\end{array}$ & $9 / 949$ & $V r / \cdots$ & 1./AT. & $V Y / I I I$ & فارخون دياستوليك (9-9) ميلى متر جيوه \\
\hline $\begin{array}{c}\mathrm{T}==_{-} / \mathrm{r} r \\
\mathrm{P}-\mathrm{value}=\cdot / \mathrm{V} \Delta .\end{array}$ & $1 \cdot / \Lambda T$. & $\wedge \vee / \Upsilon q)$ & $11 / 199$ & سMNN/I & 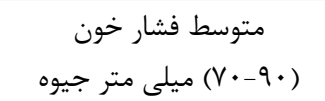 \\
\hline $\begin{array}{c}\mathrm{T}=\cdot / / 9 \mathrm{~F} \\
\text { P-value }=\cdot / \text { A } \&\end{array}$ & $11 / 1 \wedge 9$ & $\Lambda N / \backslash \Delta G$ & IF/gTt & AVIGTY & 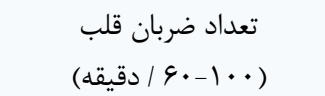 \\
\hline $\begin{array}{c}\mathrm{T}=\cdot \mid \Delta \wedge \vee \\
\text { P-value }=\cdot \mid \Delta \Delta \wedge\end{array}$ & .19. & $18 / 911$ & $\cdot / 194$ & 1911. & 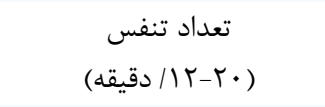 \\
\hline $\begin{array}{c}\mathrm{T}=1 / \mathrm{r} \Lambda \\
\text { P-value }=\cdot / 1 \& 9\end{array}$ & $\cdot / 491$ & rV/ISV &.$/ 49 \mathrm{~V}$ & $r V / \cdot V \Lambda$ & 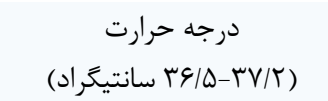 \\
\hline $\mathrm{T}=\cdot|| \Delta \mid$ & $\cdot / \cdot T_{F}$ &.$/ 9 \mathrm{rV}$ & $.1 \cdot 11$ & . 1948 & ( \\
\hline و شهريور 99 1 & ك & & & - سينا & مجله مراقبت يرستارى و \\
\hline
\end{tabular}




\begin{tabular}{|c|c|c|c|c|c|c|}
\hline آزمون Tو & \multicolumn{2}{|c|}{ مداخله } & \multicolumn{2}{|c|}{ كنترل } & \multirow{2}{*}{\multicolumn{2}{|c|}{ متغير }} \\
\hline$\pi$ & انحراف معيار & ميانگين & انحر اف معيار & ميانكين & & \\
\hline $\begin{array}{c}\mathrm{df}=\wedge \Lambda \\
\text { P-value }=\cdot / \mathrm{r} \uparrow\end{array}$ & I/OMF & $\mid F / \cdot \Lambda \Lambda$ & $\Delta / V T Y$ & $\mid \Delta / \cdot F \psi$ & قبل از انتقال & GCS \\
\hline $\begin{array}{c}\mathrm{T}=1 / \mathrm{v} \cdot q \\
\mathrm{df}=\wedge \wedge \\
\text { P-value }=\cdot / \cdot 91\end{array}$ & .1949 & IF/VTr & I/DVT & If/KGG & بعد از انتقال & \\
\hline $\begin{array}{c}\mathrm{T}=-\cdot / 419 \\
\mathrm{Df}=\wedge \wedge\end{array}$ & $1 / 019$ & ID/DTr & תr/9 & $\mid Q / G F Y$ & قبل از انتقال & \\
\hline P-value $=\cdot \mid q V \mathrm{~V}$ & & & & & & FOUR \\
\hline $\begin{array}{c}\mathrm{df}=\Lambda \Lambda \\
\mathrm{P} \text {-value }=\cdot / \uparrow \xi \cdot \mathrm{S}\end{array}$ & $1 / \cdot 9$. & $1 \Delta / V \Delta \Delta$ & سTו & ID/FFE & بعد از انتقال & \\
\hline
\end{tabular}

تستهاى آزمايشگاهى، نوع داروهاى دريافتى، تعداد و نوع

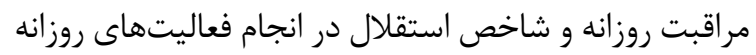
Katz مراقبين بيماران در بيمارستان در اين يروهش، اكثرا

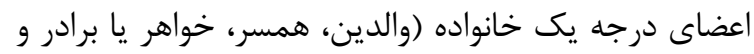

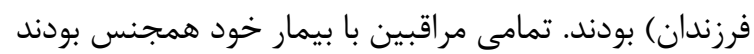

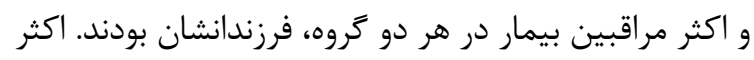
مراقبين با بيمار در يك مكان زندگى نمى مركردند. ساير مشخصات فردى بررسى شده مراقبين در اين يزوهش در دو كروه با يكديخر مشابه بود.

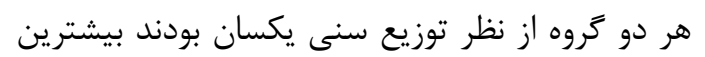
افراد شركتكننده در مطالعه مرد بودند. در گروه كنترل

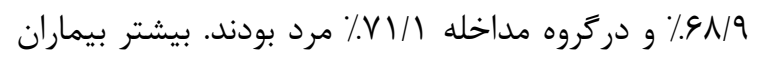

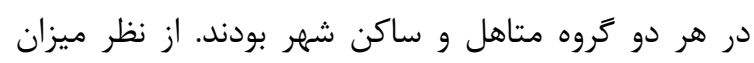
تحصيلات تفاوت معنىدارى نداشتند. بيشترين علت بسترى در هر دو گروه به علت تروما و جراحى بود. ميانكين بسترى

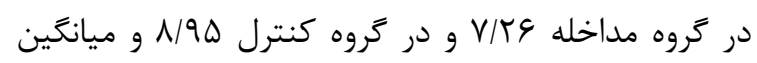
اينتوباسيون در زروه مداخله N/IF روز و در زروه كنترل

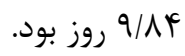

يافتههاى تحقيق نشان داد كه يرستار رابط تاثير معنى دارى بر روى يارامترهاى هموديناميك و و سطح
نتايج آزمون T مستقل در جدول فوق نشان مى دهدكه

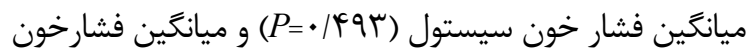

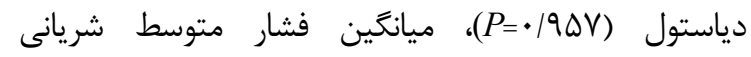

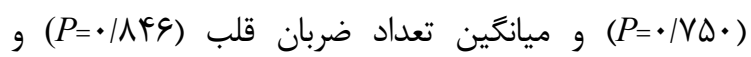

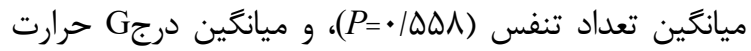

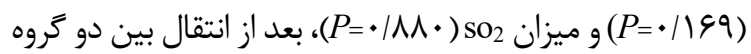
كنترل و آزمون تفاوت معنى دارى وجود ندارد. لذا هر دو گروه از اين نظر همگن بودند سطح هوشيارى بيماران توسط مقياس كلاسكو (GCS) و FOUR در هر دو گروه سنجيده شد. در مقياس GCS

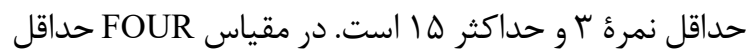

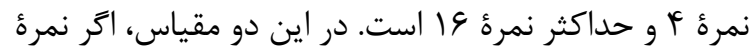

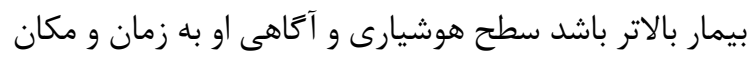

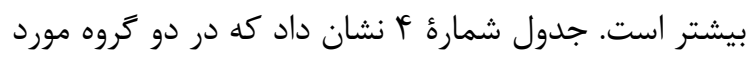
مطالعه (كنترل و مداخله) از نظر ميزان سطح هوشيارى اسى سئن

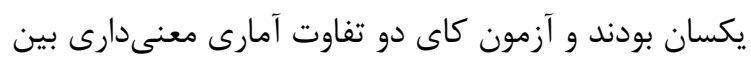
دو گروه نشان نداد.

\section{بحث}

بيماران دو گروه مداخله و كنترل از نظر ويزگىهاى فردى، تاريخجه سلامت، سطح هوشيارى، يارامترهاى 
قبل از ترخيص از بيمارستان، مجددا در ICU بسترى

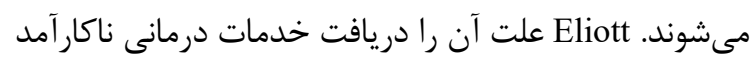

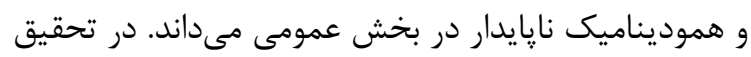

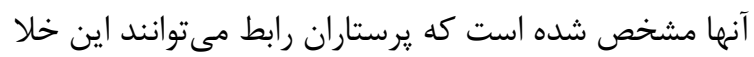

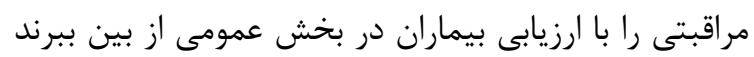

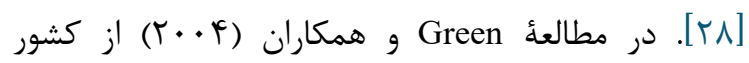
استراليا، بيان مى كند يرستار رابط برطرف كنيندة شكاف بين

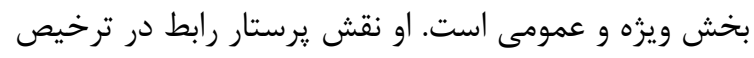

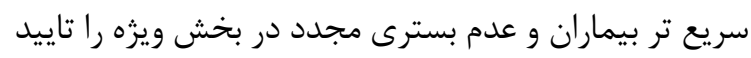

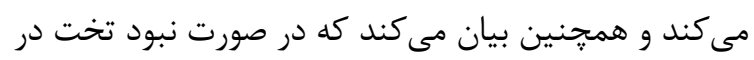
بخش ويزه، يرستاران رابط مىتوانند به خوبى از بيماران

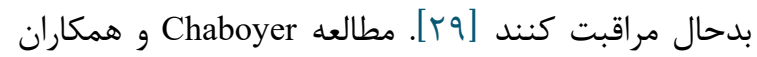

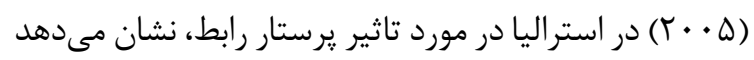

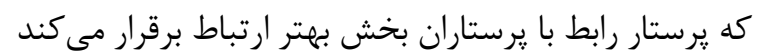

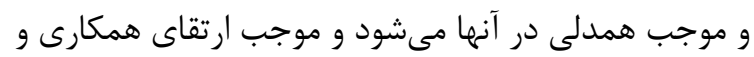

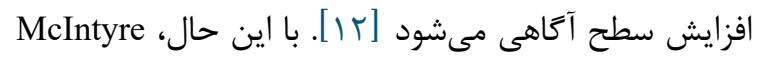

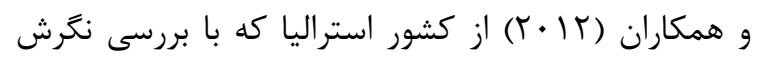
يرستاران شاغل به خدمات يرستار رابط در بيمارستان

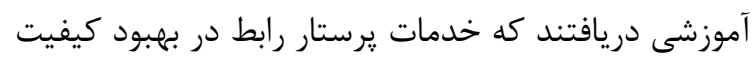

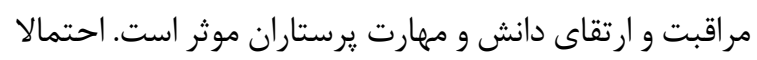

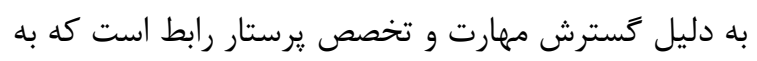

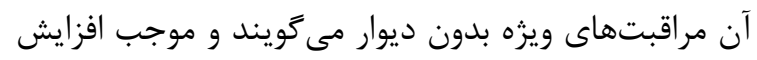

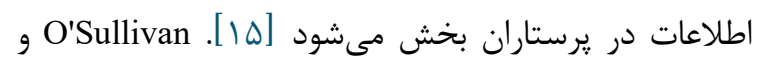

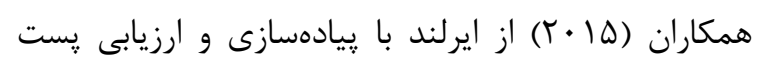

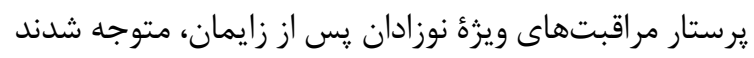

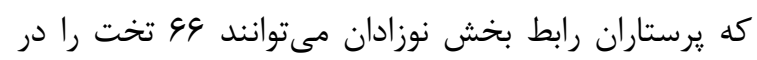

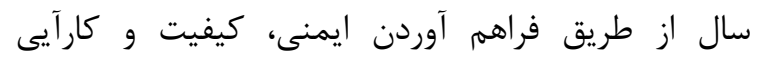

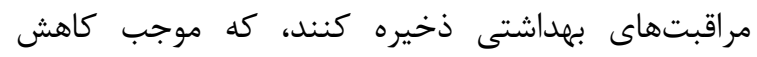

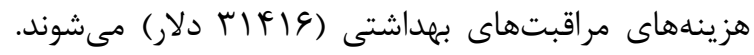

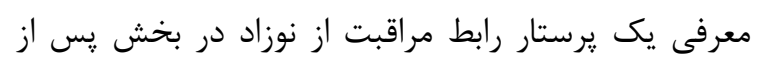

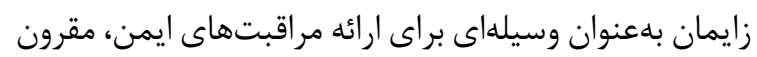

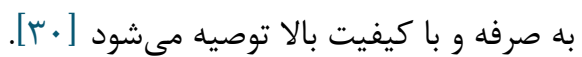
Doric

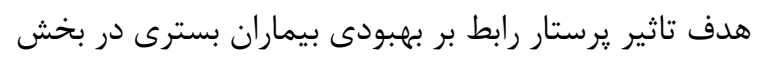

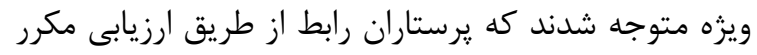

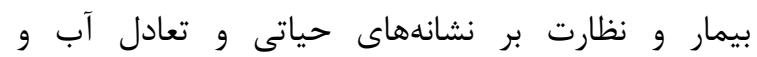

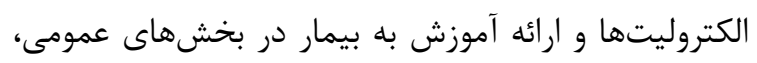

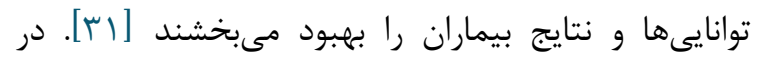

هوشيارى در بيماران انتقالى از بخش مراقبتهاى ويزه ندارد.

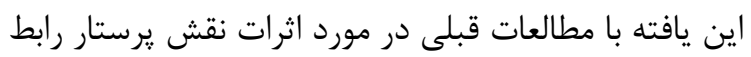

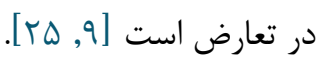
هر دو كروه از نظر فشارخون سيستول، فشار خون

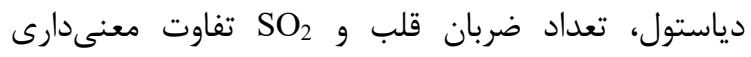

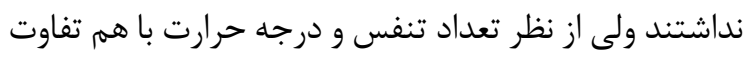
معنى دارى داشتند كه از نظر بالينى اهميتى ندارد زيرا تعداد تنفس و درجهُ حرارت در محدودههاى طبيعى هستند.

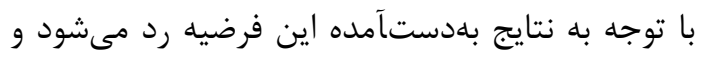

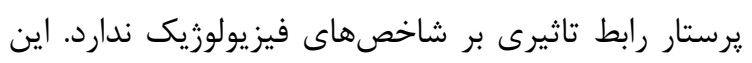

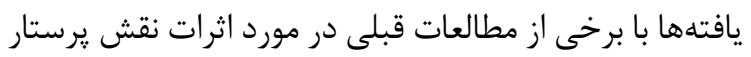

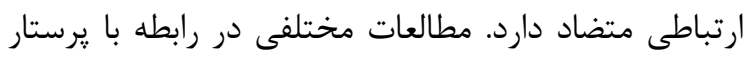

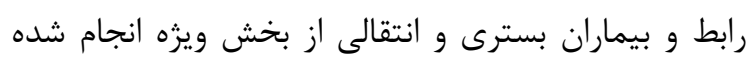

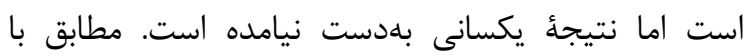

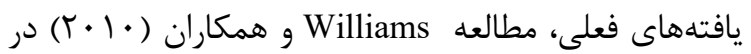

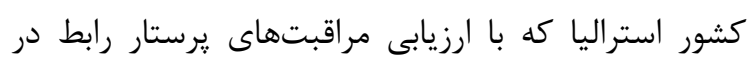

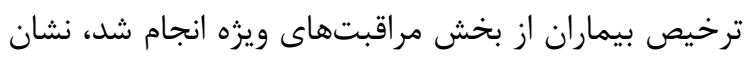

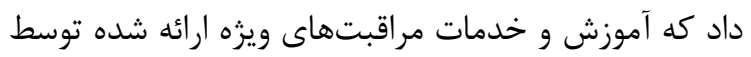

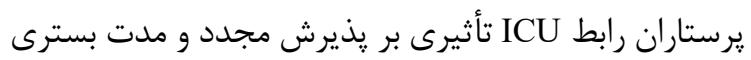

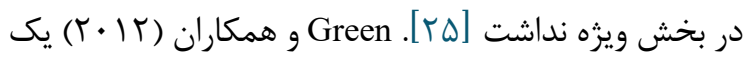
نظرسنجى در مورد يرستار رابط در استراليا انجام دادند كه طبق آن بيان كردند كه عملكردهاى يرستاران رابط يا همان

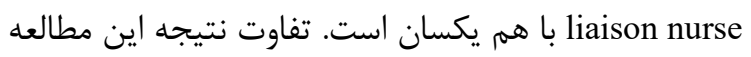
با مطالعه حاضر مىتواند به دليل مهارت و صلاحيت

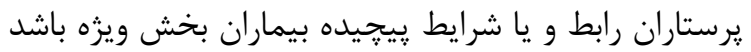

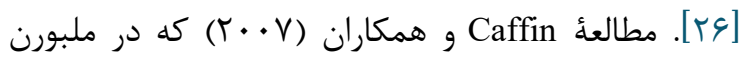
استراليا با هدف بررسى نقش يرستار رابط در بخش ويزه

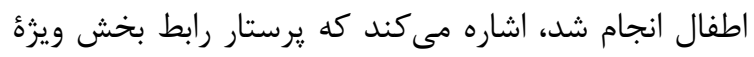

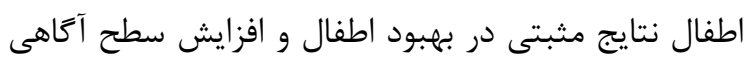

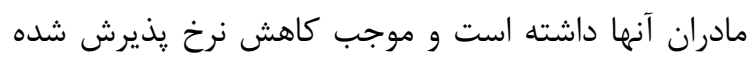

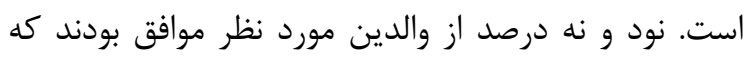
نقش LN ايده خوبى است. محقق نقش يرستار رابط را بسيار

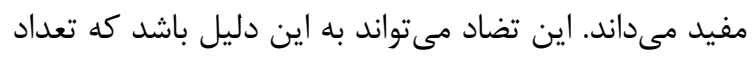

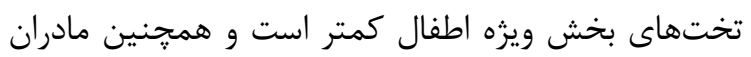

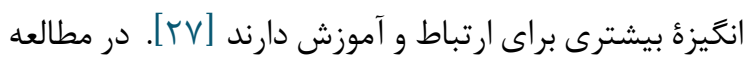
Eliott

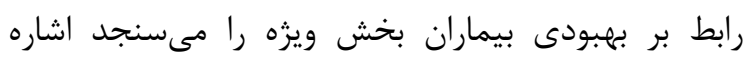

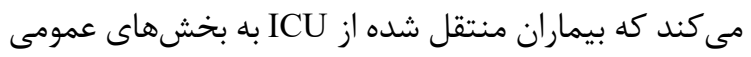


در بخش عمومى نيز مراقبت كنند و به يرستاران بخش در شناسايى و مديريت بيماران بدحال كمك كنند. يرستاران

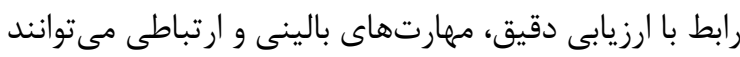

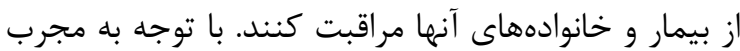
بودن و توانايى هايشان مىتوانند با تشخيص به موقع علائم

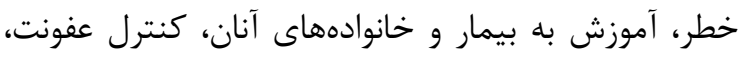

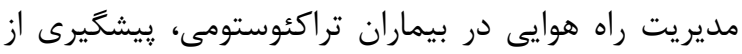

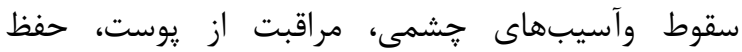
عملكردهاى فيزيكى نقش خود را براى ارتقاى سلامت ايفا

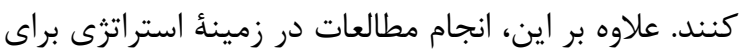
بهبود كيفيت مراقبت بعد از انتقال از بخش مراقبتهاى ويره توصيه شده است. اخر جه يرستار رابط بر شاخصهاى فيزيولوزيك و سطح هوشيارى موثر نبود اما يافتههاى اين

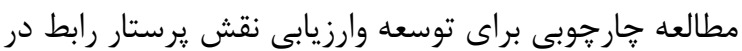

$$
\text { آينده را فراهم مى كند. }
$$

$$
\text { سياسگزارى }
$$

نويسندكان از همكارى يرستاران بخش مراقبتهاى ويره و بخش عمومى و افرادى كه در اين مطالعه شركت كردند تشكر و سياسگزارى مى كنند. همجنين مجوز از كميته اخلاق دانشگاه علوم يزشكى همدان، با كد

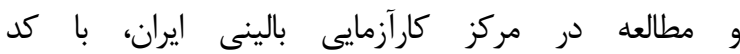
IRCT20160110025929N12

$$
\text { تعارض در منافع }
$$

بين نويسند Fان هيجز

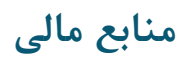

منابع مالى اين يزوهش توسط معاونت يزوهش دانشخاه علوم

$$
\text { يزشكى همدان تامين شده است. }
$$

\section{References}

1. Urden LD, Stacy KM, Lough ME. Critical Care Nursing-E-Book: Diagnosis and Management: Elsevier Health Sciences; 2017.

2. Falk A-C, Wallin E-M. Quality of patient care in the critical care unit in relation to nurse patient ratio: A descriptive study. Intensive and Critical Care

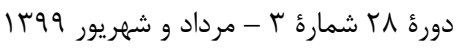

مطالعئ Tabanejad و همكاران (ع • • (Y) تاثير يرستاران رابط بر بهبود بيماران بعد از انتقال از بخش ويزه به بخش إنش عمومى بررسى شده است؛ اين مطالعه نشان مى دهد كه بين

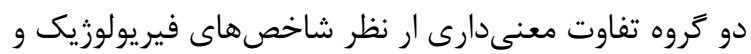

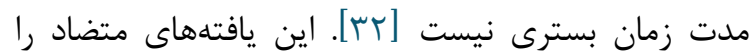

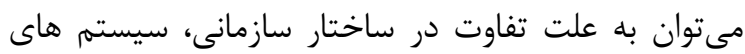

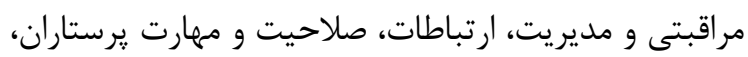
نَرَش :رستاران بخش نسبت به نقش يرستار رابط، طول

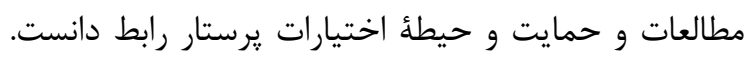

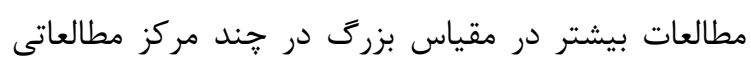

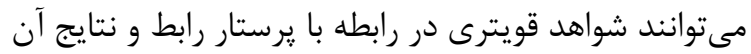
ارائه دهند. بر اين اساس، در مقياس بزرگتر، نقش يرستاران ارتباطى بيشتر قابل توجه است زيرا در جنين شرايطى ارائه مراقبتهاى تخصصى به تعداد بيشترى از بيماران ممكن بين مىشود. اين اولين مطالعه در همدان بود؛ بر اين اساس، يكى لهى

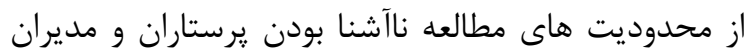
مطالعه ايجاد هماهنكَى با اين نقش بود. علاوه بر اين، در اين مطن ماين

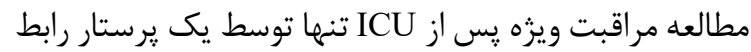
در بازه زمانى كوتاه انجام شد. تعداد نمونهها و بازه زمانى مطالعه نيز كم بود كه ممكن است بر نتايج موثر باشد.

$$
\text { نتيجه گيرى }
$$

بيماران بسترى در بخش ويزه، يك گروه آسيبذٍير با

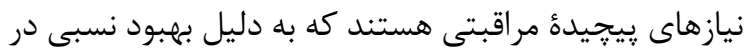

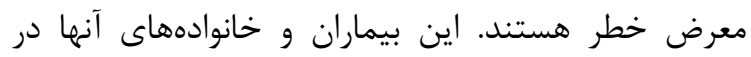

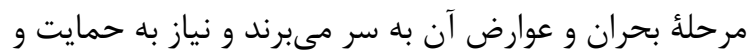

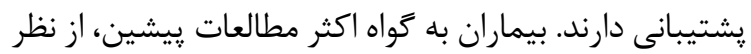

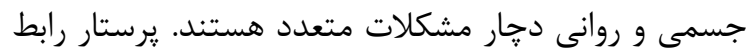

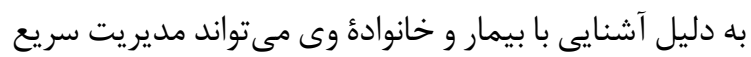
و جامعترى براى بهبود وضعيت بيمار انجام دهد. يرستاران

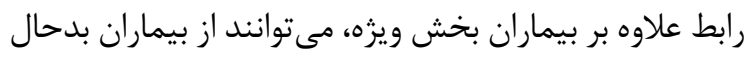

Nursing. 2016;35:74-9.

[DOI:10.1016/j.iccn.2016.01.002] [PMID]

3. Tan SS, Bakker J, Hoogendoorn ME, Kapila A, Martin J, Pezzi A, et al. Direct cost analysis of intensive care unit stay in four European countries: applying a standardized costing methodology. Value

$$
\text { مجله مراقبت يرستارى و مامايى ابنسينا }
$$


in Health. 2012;15(1):81-6. [DOI:10.1016/i.jval.2011.09.007] [PMID]

4. Corrêa TD, Ponzoni CR, Rabello Filho R, Neto AS, de Freitas Chaves RC, Pardini A, et al. Nighttime intensive care unit discharge and outcomes: A propensity matched retrospective cohort study. PloS one. 2018;13(12):e0207268.

[DOI:10.1371/journal.pone.0207268]

[PMID] [PMCID]

5. Häggström M, Asplund K, Kristiansen L. How can nurses facilitate patient's transitions from intensive care?: a grounded theory of nursing. Intensive and critical care nursing. 2012;28(4):224-33. [DOI:10.1016/j.iccn.2012.01.002] [PMID]

6. Stelfox HT, Perrier L, Straus SE, Ghali WA, Zygun $\mathrm{D}$, Boiteau $\mathrm{P}$, et al. Identifying intensive care unit discharge planning tools: protocol for a scoping review. BMJ open. 2013;3(4):e002653. [DOI:10.1136/bmjopen-2013-002653] [PMID] [PMCID]

7. Schofield-Robinson OJ, Lewis SR, Smith AF, McPeake J, Alderson P. Follow-up services for improving long-term outcomes in intensive care unit (ICU) survivors. The Cochrane database of systematic reviews. 2018;11:Cd012701. [DOI:10.1002/14651858.CD012701.pub2] [PMCID]

8. So HM, Yan WW, Chair SY. A nurse-led critical care outreach program to reduce readmission to the intensive care unit: A quasi-experimental study with a historical control group. Australian Critical Care. 2018. [DOI:10.1016/j.aucc.2018.11.005] [PMID]

9. Endacott R, Chaboyer W, Edington J, Thalib L. Impact of an ICU Liaison Nurse Service on major adverse events in patients recently discharged from ICU. Resuscitation. 2010;81(2):198-201. [DOI:10.1016/j.resuscitation.2009.10.011] [PMID]

10. Chaboyer W, Thalib L, Foster M, Ball C, Richards B. Predictors of adverse events in patients after discharge from the intensive care unit. American Journal of Critical Care. 2008;17(3):255-63. [DOI:10.4037/ajcc2008.17.3.255] [MID]

11. Chaboyer W, Lin F, Foster M, Retallick L, Panuwatwanich K, Richards B. Redesigning the ICU nursing discharge process: a quality improvement study. Worldviews on Evidence-Based Nursing. 2012;9(1):40-8. 6787.2011.00234.x] [PMID]

[DOI:10.1111/j.1741-

12. Chaboyer W, Gillespie B, Foster M, Kendall M. The impact of an ICU liaison nurse: a case study of ward nurses' perceptions. Journal of clinical nursing. 2005;14(6):766-75. 2702.2005.01141.x] [PMID]

13. Alberto L, Zotárez H, Cañete ÁA, Niklas JEB, Enriquez JM, Gerónimo MR, et al. A description of the ICU liaison nurse role in Argentina. Intensive and Critical Care Nursing. 2014;30(1):31-7. [DOI:10.1016/j.iccn.2013.07.001] [PMID]

14. Hesselink G, Zegers M, Vernooij-Dassen M, Barach P, Kalkman C, Flink M, et al. Improving patient discharge and reducing hospital readmissions by using Intervention Mapping. BMC health services research. 2014;14(1):389. [DOI:10.1186/1472-696314-389] [PMID] [PMCID]

15. McIntyre T, Taylor C, Eastwood GM, Jones D, Baldwin I, Bellomo R. A survey of ward nurses attitudes to the Intensive Care Nurse Consultant service in a teaching hospital. Australian Critical Care. 2012;25(2):100-9. [DOI:10.1016/j.aucc.2011.10.003] [PMID]

16. Adam S, Osborne S, Welch J. Critical care nursing: science and practice: Oxford University Press; 2017. [DOI:10.1093/med $/ 9780199696260.001 .0001]$ [PMID]

17. Stelfox HT, Lane D, Boyd JM, Taylor S, Perrier L, Straus $\mathrm{S}$, et al. A scoping review of patient discharge from intensive care: opportunities and tools to improve care. Chest. 2015;147(2):317-27. [DOI:10.1378/chest.13-2965] [PMID]

18. Fry M. Literature review of the impact of nurse practitioners in critical care services. Nursing in critical care. 2011;16(2):58-66. [DOI:10.1111/j.1478-5153.2010.00437.x] [PMID]

19. Choi J, Tate JA, Rogers MA, Donahoe MP, Hoffman LA. Depressive symptoms and anxiety in intensive care unit (ICU) survivors after ICU discharge. Heart \& Lung: The Journal of Acute and Critical Care. 2016;45(2):140-6.

[DOI:10.1016/j.hrtlng.2015.12.002] [PMCID]

[PMID]

20. Dolatyari A, Sharififar S, ZAREIYAN A, TADRISI SD. Family satisfaction with care in the intensive care unit: Results of a multiple center study in selected military hospitals. 2014. [DOI:10.18869/acadpub.mcs.1.1.18]

21. Rosa R, Ascoli A, Rutzen W, Madeira L, Falavigna M, Robinson C, et al. Factors associated with hospital anxiety and depression among ICU survivors: a cross sectional study. Intensive care medicine experimental. 2015;3(S1):A369. [DOI:10.1186/2197-425X-3-S1-A369] [PMCID]

22. Niven DJ, Bastos JF, Stelfox HT. Critical care transition programs and the risk of readmission or death after discharge from an ICU: a systematic review and meta-analysis. Critical care medicine. 2014;42(1):179-87.

[DOI:10.1097/CCM.0b013e3182a272c0] [PMID]

23. Day A, Haj-Bakri S, Lubchansky S, Mehta S. Sleep, anxiety and fatigue in family members of patients admitted to the intensive care unit: a questionnaire study. Critical Care. 2013;17(3):R91. [DOI:10.1186/cc12736] [PMID] [PMCID]

24. McAdam JL, Fontaine DK, White DB, Dracup KA, Puntillo KA. Psychological symptoms of family members of high-risk intensive care unit patients. American journal of critical care : an official publication, American Association of Critical-Care Nurses. 2012;21(6):386-93; quiz 94. [DOI:10.4037/ajec2012582] [PMID]

25. Williams TA, Leslie G, Finn J, Brearley L, Asthifa M, Hay B, et al. Clinical effectiveness of a critical 


$$
\text { رrr تاثير نقش يرستار رابط بر شاخصهاى فيزيولوزيك و سطح هوشيارى بيماران انتقالى }
$$

care nursing outreach service in facilitating discharge from the intensive care unit. American Journal of Critical Care. 2010;19(5):e63-e72. [DOI:10.4037/ajcc2010965] [PMID]

26. Anna Green, Tammie McIntyre, Carmel Taylor, Wendy Chaboyer, Daryl Jones, Malcolm Elliot and et al,. Uptake and caseload of intensive care unit liaison nurse services in Australia. Critical care and resuscitation: journal of the Australasian Academy of Critical Care Medicine. 2012;14(3):221. [PMID]

27. Caffin CL, Linton S, Pellegrini J. Introduction of a liaison nurse role in a tertiary paediatric ICU. Intensive and Critical Care Nursing. 2007;23(4):22633. [DOI:10.1016/j.iccn.2006.12.001] [PMID]

28. Elliott M, Worrall-Carter L, Page K. Factors contributing to adverse events after ICU discharge: a survey of liaison nurses. Australian Critical Care. 2013;26(2):76-80.

[DOI:10.1016/j.aucc.2012.07.005] [PMID]

29. Green A, Edmonds L. Bridging the gap between the intensive care unit and general wards-the ICU Liaison Nurse. Intensive and Critical Care Nursing. 2004;20(3):133-43. [DOI:10.1016/S09643397(04)00024-2]

30. O'sullivan A, Boyd B, O'shaughnessy M, MacIntyre A, Begley C. Evaluation of the introduction of a postnatal ward liaison neonatal nurse. Journal of Neonatal Nursing. 2015;21(1):34-9. [DOI:10.1016/j.jnn.2014.07.003]

31. Doric A, Ernest D, Thalib L, Page KN, Chaboyer W, Eliott $\mathrm{S}$, et al. The impact of an ICU liaison nurse service on patient outcomes. Critical Care and Resuscitation. 2008;10(4):296.

32. Tabanejad Z, Pazokian M, Ebadi A. The Effect of Liaison Nurse Service on Patient Outcomes after Discharging From ICU: a Randomized Controlled Trial. Journal of caring sciences. 2016;5(3):215. [DOI:10.15171/jcs.2016.023] [PMID] [PMCID] 